\title{
Evidence for genetic heterogeneity in Best's vitelliform macular dystrophy
}

Wellcome Ocular

Genetics Unit,

Genetics Department,

Trinity College,

Dublin 2, Ireland

F C Mansergh

P F Kenna

G J Farrar

R Kumar-Singh

J Scorer

A M Hally

L Mynett-Johnson

M M Humphries

$S$ Kiang

P Humphries

\section{Abteilung für}

paediatrische Genetik, Kinderpoliklinik,

Ludwig-Maximilians-

Universitat München,

Genetische

Beratungsstelle,

Goethestrasse 29,

80336 München,

Germany

T Meitinger

Augenklinik, LudwigMaximilians-

Universitat München,

Mathildenstrasse 6,

80336 München,

Germany

G Rudolph

Research Foundation, Eye and Ear Hospital, Dublin 2, Ireland P F Kenna

Correspondence to: Dr Mansergh.

Received 15 May 1995 Revised version accepted for publication 11 July 1995

\begin{abstract}
Best's vitelliform macular dystrophy is an early onset, autosomal dominant macular degeneration. Linkage analysis has previously mapped a disease locus in this disorder to the pericentromeric region of chromosome 11. We examined two families, one of German and one of Irish origin, both affected with this disorder. The Irish family (BTMD1) showed strong evidence for linkage to the previously reported locus on chromosome 11. Linkage of the disease locus to the same region of chromosome 11 has been significantly excluded in the German family (Fam E), thereby providing evidence of locus heterogeneity in this clinically unique condition.
\end{abstract}

( $\mathcal{}$ Med Genet 1995;32:855-858)

Best's macular dystrophy was first characterised in $1905 .^{1}$ This retinal degeneration primarily affects the macular area, the cone-photoreceptor rich region situated temporal to the optic disc and centred on the fovea. In the initial stages a characteristic yellowish subretinal blister occurs which is accurately described as looking like a fried egg. As the condition progresses, the blister flattens and the lesion takes on an appearance resembling a "scrambled egg". At this stage the patient has a central scotoma and notices significant disturbance of vision, Snellen visual acuity being reduced to $6 / 60$ or less. As the disease progresses, an atrophic scar forms at the macula (fig 1). Even before the appearance of the initial retinal lesion, an absence of the light induced rise in amplitude of the electro-oculogram (EOG) can be detected. The so-called Arden Index (light peak/dark trough), which is normally greater than 1.6 , is invariant, that is, 1.0 . This test can be used to make a presymptomatic diagnosis in at risk subjects. ${ }^{2}$ The condition is inherited in an autosomal dominant manner, and is early onset, but otherwise shares certain clinical features with age related forms of macular degeneration, one of the most common forms of severe visual impairment in the elderly. Identification of the precise molecular causes of pathogenesis in Best's disease could further the understanding of the pathologies of other, more common forms of macular degeneration.

To date, the Best's macular dystrophy locus has been found to map exclusively to the pericentromeric region of chromosome 11 . The initial study showed linkage of the disease locus to a region between markers D11S871 and INT2. ${ }^{34}$ Using further polymorphic markers, this region was later narrowed down to the interval between D11S986 in band p12-11.22 and D11S480 in band q13.2-13.3. ${ }^{56}$

We have performed linkage studies in two families, one of Irish and one of German origin,

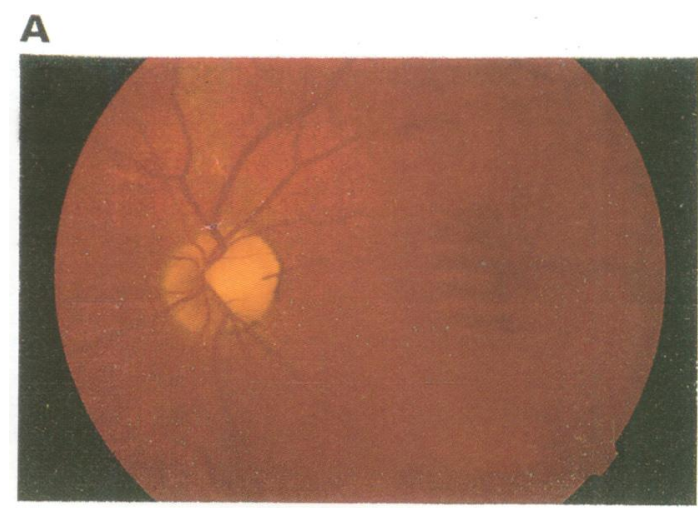

B

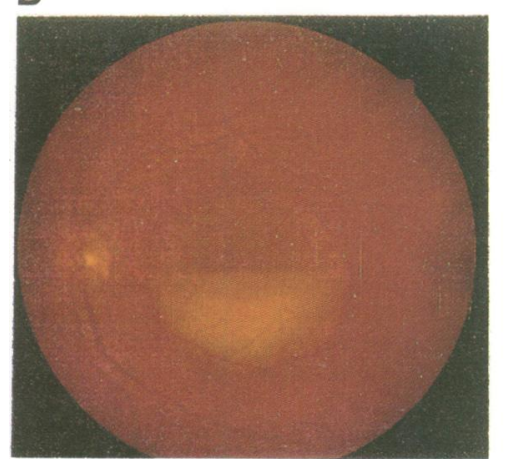

C

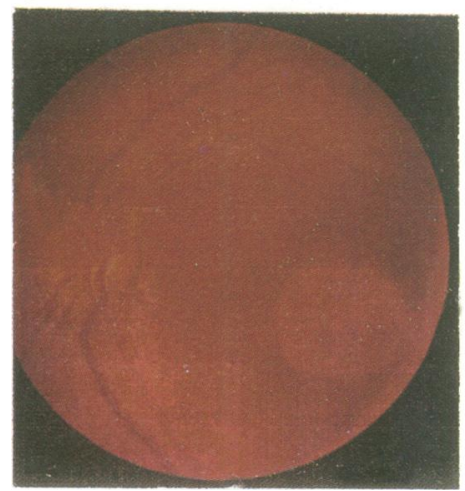

Figure 1 (A) Fundus photograph of a normal eye. (B) Fundus photograph of an affected subject from Fam E. A yellow lipofuscin blister is visible in the macular region. (C) Fundus photograph of an affected subject from the Irish pedigree BTMD1. 


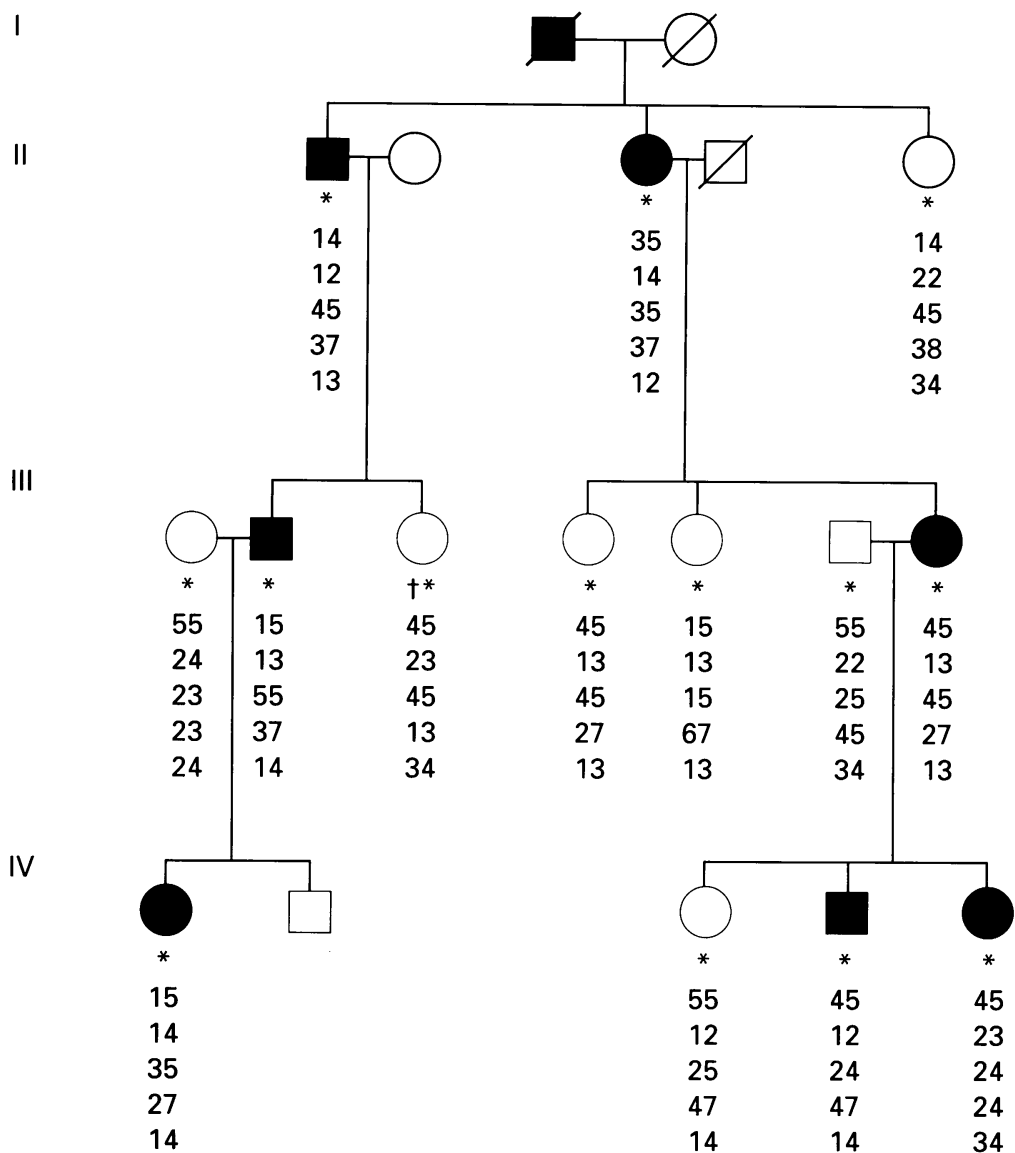

Figure 2 Pedigree of Fam E. Subjects for whom DNA was available are indicated by an asterisk. The unaffected subject not examined by EOG is indicated by a cross. All related subjects have undergone a thorough ophthalmological examination. Haplotype reconstructions for the following markers are given, from top to bottom: D11S905, D11S1355, D11S903, D11S986, and D11S1357.

both segregating typical Best's macular dystrophy. Results in the Irish family (BTMD1) localise the disease locus to the above region of chromosome 11. Linkage of the disease locus has been significantly excluded from this region in the German family (Fam E), thereby providing evidence of genetic heterogeneity in a disorder which shows a great degree of clinical homogeneity.

Forty-three subjects were chosen for analysis in family BTMD1, of whom 19 were affected; corresponding information for Fam $\mathrm{E}$ is given in fig 2. Subjects were examined by electrooculography using a standard protocol. ${ }^{2}$ Persons were considered to be affected for purposes of linkage study if they displayed an Arden ratio of less than 1.6, and were considered to be unaffected if they displayed an Arden ratio of greater than 1.6. Patients' DNA was prepared from pelleted blood lymphocytes using standard protocols. Primer sequences for microsatellite markers were obtained from the published linkage papers, ${ }^{3-6}$ the Genethon map, ${ }^{7}$ and from other sources, including GDB. Markers were typed in the families by PCR amplification, involving incorporation of $\alpha^{32}$ PdCTP radiolabel into PCR products using a standard protocol, and electrophoresed on $8 \%$, denaturing acrylamide gels. Computations of data obtained from autoradiograms were performed using the LINKSYS version 4.11 data management package. ${ }^{8}$ Calculations were performed using LIPED for two point analyses, except under conditions of reduced penetrance, where MLINK version 5.1 was used. Multipoints were executed using LINKMAP, version 5.1 , and LINKAGE version 5.1 on a $512 \mathrm{~K}$ PC. ${ }^{9}$ Allele frequencies and male/female recombination ratios were taken to be equal for purposes of all analyses.

The disease locus in the Irish family (BTMD1) was mapped by linkage analysis to chromosome 11 in the $10 \mathrm{cM}$ region between the flanking markers PYGM and D11S871, which encompasses markers D11S986 and D11S480 (table 1). We were unable to narrow this interval any further in this family. This places the disease locus in BTMD1 in the same

Table 1 Two point lod scores between the Best's vitelliform macular dystrophy locus and loci on the pericentromeric region of chromosome 11, showing exclusion of the Best's disease gene in the German pedigree Fam E, and linkage in the Irish pedigree BTMD1. The bold numbers indicate the lod scores showing significant exclusion at the corresponding recombination fraction for each marker locus. Data re-analysed for various markers, incorporating different estimates of disease locus penetrance, is also shown, in the case of Fam E (1.0 indicates full penetrance). Penetrance was not reduced in the case of family BTMD1, as no recombinants were observed between the disease locus and the most closely linked markers. PYGM was uninformative in Fam E.

\begin{tabular}{|c|c|c|c|c|c|c|c|c|}
\hline \multirow[t]{2}{*}{ Locus } & \multirow[t]{2}{*}{ Penetrance } & \multicolumn{7}{|c|}{ Recombination fraction $(\theta)$} \\
\hline & & 0.00 & 0.001 & 0.05 & 0.10 & 0.15 & 0.20 & Family \\
\hline \multirow[t]{5}{*}{ D11S871 } & 1.0 & -99.9 & -10.2 & -3.44 & -2.29 & -1.63 & -1.18 & Fam E \\
\hline & 0.9 & -8.52 & -6.54 & -3.02 & -2.05 & -1.47 & -1.08 & Fam E \\
\hline & 0.8 & -7.72 & -6.08 & -2.83 & -1.92 & -1.37 & -1.01 & Fam E \\
\hline & 0.7 & -7.24 & -5.80 & -2.72 & -1.83 & -1.31 & -0.95 & Fam E \\
\hline & 1.0 & -99.9 & 3.91 & 5.06 & 4.78 & 4.33 & 3.80 & BTMD1 \\
\hline \multirow[t]{5}{*}{ D11S905 } & 1.0 & -99.9 & -12.3 & -3.91 & -2.51 & -1.75 & -1.24 & Fam E \\
\hline & 0.9 & -8.01 & -6.05 & -3.42 & -2.27 & -1.61 & -1.15 & Fam E \\
\hline & 0.8 & -7.40 & -5.75 & -3.16 & -2.12 & -1.50 & -1.08 & Fam E \\
\hline & 0.7 & -7.04 & -5.59 & -2.97 & -2.01 & -1.42 & -1.02 & Fam E \\
\hline & 1.0 & 2.10 & 2.10 & 1.98 & 1.84 & 1.68 & 1.50 & BTMD 1 \\
\hline \multirow[t]{3}{*}{ D11S1355 } & 1.0 & -99.9 & -8.99 & -2.37 & -1.35 & -0.83 & -0.52 & Fam E \\
\hline & 0.9 & -4.90 & $-\mathbf{3 . 1 8}$ & -1.19 & -0.71 & -0.44 & -0.27 & Fam E \\
\hline & 1.0 & 2.14 & 2.13 & 1.95 & 1.76 & 1.57 & 1.36 & BTMD1 \\
\hline \multirow[t]{5}{*}{ D11S903 } & 1.0 & -99.9 & -13.01 & -4.54 & -3.07 & -2.22 & -1.63 & Fam E \\
\hline & 0.9 & -6.03 & -5.97 & -3.43 & -2.22 & -1.85 & -1.39 & Fam E \\
\hline & 0.8 & -4.88 & -4.87 & -2.87 & -2.10 & -1.60 & -1.22 & Fam E \\
\hline & 0.7 & -4.25 & -4.24 & -2.52 & -1.84 & -1.41 & -1.09 & Fam E \\
\hline & 1.0 & 6.83 & 6.81 & 6.27 & 5.69 & 5.07 & 4.42 & BTMD1 \\
\hline \multirow[t]{3}{*}{ D11S986 } & 1.0 & -99.9 & -9.29 & -2.65 & -1.62 & -1.08 & -0.74 & Fam E \\
\hline & 0.9 & -5.20 & -3.48 & -1.52 & -1.02 & -0.71 & -0.51 & Fam E \\
\hline & 1.0 & 9.12 & 9.10 & 8.39 & 7.59 & 6.75 & 5.86 & BTMD1 \\
\hline \multirow[t]{3}{*}{ D11S1357 } & 1.0 & -99.9 & -8.99 & -2.37 & -1.35 & -0.83 & -0.52 & Fam E \\
\hline & 0.9 & -4.89 & $-\mathbf{3 . 1 8}$ & -1.19 & -0.71 & -0.44 & -0.27 & Fam E \\
\hline & 1.0 & 6.92 & 6.91 & 6.34 & 5.73 & 5.09 & 4.41 & BTMD1 \\
\hline PYGM & 1.0 & -99.9 & 2.01 & 4.85 & 4.86 & 4.57 & 4.14 & BTMD1 \\
\hline
\end{tabular}


Table 2 Two point lod scores between Best's macular dystrophy and markers situated in the region of various candidate loci (see text), showing exclusion of the Best's disease locus from these regions in the German pedigree Fam $E$ (Ref refers to papers from which information as to regions of interest, or markers run below, was obtained). The bold numbers indicate the lod scores showing significant exclusion at the corresponding recombination fraction for each marker locus

\begin{tabular}{|c|c|c|c|c|c|c|c|c|}
\hline \multirow[t]{2}{*}{ Locus } & \multicolumn{6}{|c|}{ Recombination fraction $(\theta)$} & \multirow[t]{2}{*}{ Ref } & \multirow[t]{2}{*}{ Map location } \\
\hline & 0.00 & 0.001 & 0.05 & 0.10 & 0.15 & 0.20 & & \\
\hline $\begin{array}{l}\text { D1S207 } \\
\text { F13B } \\
\text { D6S251 } \\
\text { D6S249 } \\
\text { D6S280 } \\
\text { RDS } \\
\text { DS7S486 } \\
\text { D7S514 } \\
\text { D7S480 } \\
\text { D7S493 } \\
\text { D7S460 } \\
\text { D7S485 } \\
\text { D7S526 } \\
\text { D13S158 } \\
\text { D22S275 }\end{array}$ & $\begin{array}{l}-99.9 \\
-99.9 \\
-99.9 \\
-99.9 \\
-99.9 \\
-99.9 \\
-99.9 \\
-99.9 \\
-99.9 \\
-99.9 \\
-99.9 \\
-99.9 \\
-99.9 \\
-99.9 \\
-99.9\end{array}$ & $\begin{array}{l}-12.0 \\
-7.19 \\
-10.2 \\
-7.20 \\
-7.19 \\
-9.74 \\
-9.59 \\
-11.9 \\
-7.43 \\
-9.29 \\
-9.68 \\
-5.57 \\
-4.50 \\
-12.3 \\
-10.4\end{array}$ & $\begin{array}{l}-3.61 \\
-2.16 \\
-3.43 \\
-2.19 \\
-2.13 \\
-2.98 \\
-2.90 \\
-3.62 \\
-2.28 \\
-2.63 \\
-2.98 \\
-2.07 \\
-2.44 \\
-3.89 \\
-3.69\end{array}$ & $\begin{array}{l}-2.21 \\
-1.33 \\
-2.24 \\
-1.39 \\
-1.29 \\
-1.86 \\
-1.81 \\
-2.26 \\
-1.38 \\
-1.55 \\
-1.88 \\
-1.39 \\
-1.59 \\
-2.48 \\
-2.54\end{array}$ & $\begin{array}{l}-1.46 \\
-0.87 \\
-1.57 \\
-0.96 \\
-0.84 \\
-1.23 \\
-1.22 \\
-1.53 \\
-0.90 \\
-0.99 \\
-1.28 \\
-0.98 \\
-1.11 \\
-1.70 \\
-1.88\end{array}$ & $\begin{array}{l}-0.96 \\
-0.58 \\
-1.12 \\
-0.68 \\
-0.55 \\
-0.82 \\
-0.84 \\
-1.05 \\
-0.59 \\
-0.64 \\
-0.89 \\
-0.69 \\
-0.79 \\
-1.19 \\
-1.43\end{array}$ & $\begin{array}{l}11 \\
20 \\
12 \\
12 \\
15 \\
21 \\
19 \\
19 \\
19 \\
19 \\
17 \\
17 \\
14 \\
16 \\
13\end{array}$ & $\begin{array}{l}1 \mathrm{p} \\
1 \mathrm{q} \\
6 \mathrm{q} \\
6 \mathrm{q} \\
6 \mathrm{q} \\
6 \mathrm{p} \\
7 \mathrm{q} \\
7 \mathrm{q} \\
7 \mathrm{q} \\
7 \mathrm{p} \\
7 \mathrm{p} \\
7 \mathrm{p} \\
7 \mathrm{p} \\
13 \mathrm{q} \\
22 \mathrm{q}\end{array}$ \\
\hline
\end{tabular}

location as previously reported. ${ }^{3-6}$ In contrast, linkage of the disease locus has been significantly excluded from this region of chromosome 11 in Fam E (table 1). Five markers spanning the region of interest were used to perform multipoint analyses (fig 3), including D11S986, which has been shown to be one of the markers most closely linked to the disease locus. ${ }^{5}$ Most two point and all multipoint analyses were repeated under conditions of reduced penetrance. The penetrance of the disease locus was reduced for two reasons: firstly because, although Best's disease has traditionally been accorded the status of a fully penetrant autosomal dominant disorder, cases of reduced penetrance have been observed. ${ }^{10}$ A penetrance value of 0.96 has recently been provisionally assigned for the disorder. ${ }^{10} \mathrm{Sec}-$ ondly, one unaffected members of Fam $\mathrm{E}$ was unavailable for examination by EOG, although she had previously undergone an ophthalmological examination. Given the age of this person, it is extremely unlikely that a misdiagnosis has occurred, but in order to allow for this possibility, penetrance was lowered to $0.9,0.8$, and 0.7 in some of the analyses. Even

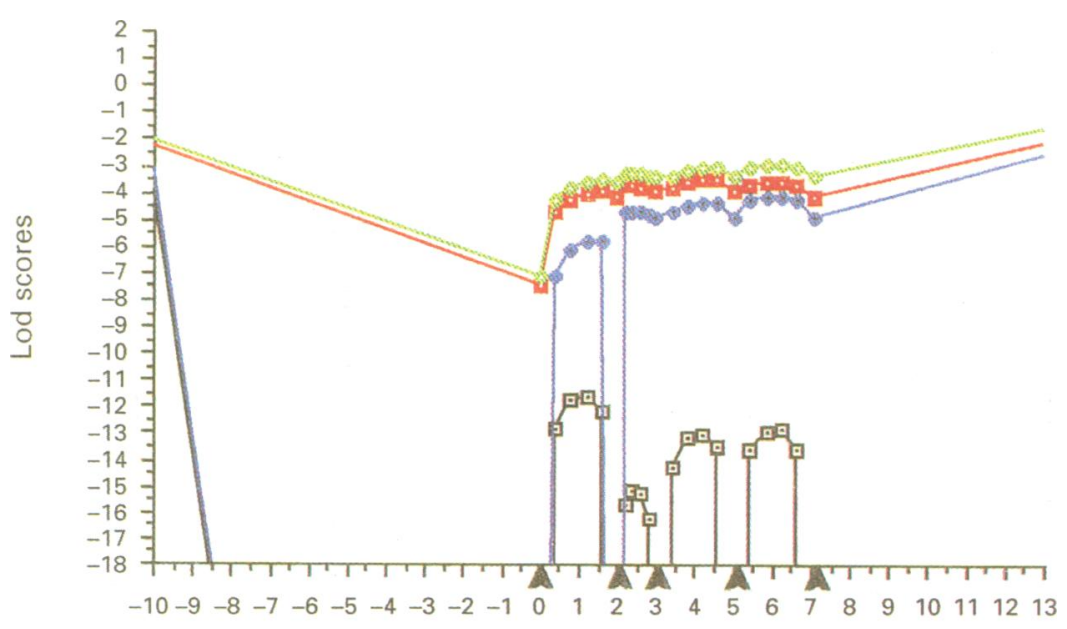

$\mathrm{cM}$

Figure 3 Multipoint analyses of Fam E performed using LINKMAP. Marker distances are indicated above. Marker order, from left to right, is D11S905, D11S1355, D11S903, D111S986, and D11S1357. Varying estimates of penetrance were used; black indicates a penetrance of 1.0, blue indicates a value of 0.9 , red indicates a value of 0.8 , and green indicates a value of 0.7 . at a penetrance of 0.7 , significant exclusions were obtained (table 2 , fig 3 ). These results provide the first evidence of genetic heterogeneity in Best's macular dystrophy, and complement the growing body of data which show a complex genetic aetiology and extensive intraand intergenetic heterogeneity in degenerative retinopathies.

Regions other than $11 \mathrm{p} 12-\mathrm{q} 13$, shown to be linked to other forms of macular and retinal degenerations, have also been examined for linkage in this family (see table 2 for lod scores). The region of chromosome 1 linked to the Stargardt's disease locus has been excluded, ${ }^{11}$ as has the North Carolina macular dystrophy locus on chromosome $6 \mathrm{q},{ }^{12}$ the Sorsby's fundus dystrophy locus on $22 \mathrm{q},{ }^{13}$ the dominant cystoid macular dystrophy gene on $7 \mathrm{p},{ }^{14}$ the Stargardtlike dominant progressive macular dystrophy on $6 \mathrm{q},{ }^{15}$ and the dominant Stargardt's macular dystrophy locus on $13 \mathrm{q} 34 .{ }^{16}$ We have also excluded the involvement of the RDS/peripherin gene on $6 \mathrm{p}$, the regions of linkage to autosomal dominant retinitis pigmentosa (ADRP) on chromosome $7 p$ and $7 q,{ }^{17-19}$ and the region of $1 \mathrm{q}$ linked to autosomal recessive retinitis pigmentosa (ARRP). ${ }^{20}$ As defects in the RDS/ peripherin gene have been shown to be the cause of both $\mathrm{ADRP}^{2122}$ and various other forms of macular and retinal degeneration, ${ }^{23-25}$ it is reasonable to examine any region known to be involved in the pathogenesis of a retinal degeneration for linkage in this family; however, owing to its size, definitive exclusion of all candidate regions has not been possible.

This work was supported by the Wellcome Trust, the US Foundation Fighting Blindness, RP Ireland Fighting Blindness, the British RP Association, the Science Programme of the European Union, the Deutsche Forschungsgemeinschaft, and the Ulverscroft Foundation (UK). We would also like to thank Andreas Gal, Edwin Stone, and Jean Weissenbach for helpful information and assistance provided. Clinical evaluation of members of BTMD1 was carried out at the Research Foundation, Eye and Ear Hospital, Dublin 2, Ireland, to whom we are grateful for assistance. We would also like to thank Denis Shields for his help with the computer analysis.

1 Best RZ. Über eine hereditäre Maculaaffektion: Beiträge zur Vererbungslehre, $Z$ Augenheilkd 1905;13:199-212.

2 Arden GB, Barrada A, Kelsey JH. New clinical test of retinal function based on the standing potential of the eye. $B r f$ function based on the standing

3 Stone EM, Nichols BE, Streb LM, Kimura AE, Sheffield VC. Genetic linkage of vitelliform macular degeneration (Best's disease) to chromosome 11 q13. Nature Genet 1992; 1:246-50. 
4 Forsman K, Graff C, Nordstrom S, et al. The gene for Best's macular dystrophy is located at $11 \mathrm{q} 13$ in a Swedish family. Clin Genet 1992;42:156-9.

5 Weber BH, Vogt G, Stohr H, Sander S, Walker D, Jones C. High resolution meiotic and physical mapping of the Best vitelliform macular dystrophy (VMD2) locus to pericentromeric chromosome 11. Am f Hum Genet 1994;55 $1182-7$

6 Weber BH, Walker D, Muller B, Mar L. Best's vitelliform dystrophy (VMD2) maps between D11S903 and PYGM no evidence for locus heterogeneity. Genomics 1994;20: 267-74.

7 Gyapay G, Morisette J, Vignal A, et al. The 1993-1994 Genethon human genetic linkage map. Nature Genet 1994; 6:246-339.

8 Attwood J, Bryant S. A computer programme to make analysis with LIPED and LINKAGE easier to perform and less prone to input errors. Ann Hum Genet 1988;52: 259.

9 Lathrop GM, Lalouel JM, Julier C, Ott J. Multilocus linkage analysis in humans: detection of linkage and estimation of

10 Weber BH, Walker D, Muller B. Molecular evidence for non-penetrance in Best's disease. 7 Med Genet 1994;31: 388-92.

11 Kaplan J, Gerber S, Larget-Piet D, et al. A gene for Stargardt's disease (fundus flavimaculatus) maps to the shor

12 Small KW, Weber JL, Roses A, Lennon F, Vance JM Pericak-Vance MA. North Carolina macular dystrophy is ssigned to chromosome 6. Genomics 1992;13:681-5.

13 Weber BH, Vogt G, Wolz W, Ives EJ, Ewing CC. Sorsby's fundus dystrophy is genetically linked to chromosome 22q13-qter. Nature Genet 1994;7:158-61.

14 Kremer H, Pinckers A, van den Helm B, Deutman AF, Ropers HH, Mariman EC. Localization of the gene for dominant cystoid macular dystrophy on chromosome $7 \mathrm{p}$ Hum Mol Genet 1994;3:299-302.

15 Stone EM, Nichols BE, Kimura AE, Weingeist TA, Drack A, Sheffield VC. Clinical features of a Stargardt-like dom- inant progressive macular dystrophy with genetic linkage to chromosome 6q. Arch Ophthalmol 1994;112:765-72.

16 Zhang K, Bither PP, Park R, Donoso LA, Seidmann JG Seidmann CE. A dominant Stargardt's macular dystrophy locus maps to chromosome 13q34. 112:759-64.

17 Inglehearn CF, Carter SA, Keen TJ, et al. A new locus for autosomal dominant retinitis pigmentosa on chromosome 7p. Nature Genet 1993;4:51-3.

18 Inglehearn CF, Keen TG, Al-Magtheh M, et al. Furthe refinement of the location for autosomal dominant retiniti pigmentosa on chromosome 7p. Am $\mathcal{F}$ Hum Genet 1994 54:675-80.

19 Jordan SA, Farrar GJ, Kenna P, et al. Localization of an autosomal dominant retinitis pigmentosa gene to chromosome 7q. Nature Genet 1993;4:54-8.

20 Van Soest S, van den Born L, Gal A, et al. Assignment of a gene for autosomal recessive retinitis pigmentosa (RP12) to chromosome 1q31-q32.1 in an inbred and genetically heterogeneous disease population. Genomics 1994;22:499504.

21 Farrar GJ, Kenna P, Jordan SA, et al. A three base pair deletion in the peripherin/RDS gene in one form of retinitis deletion in the peripherin/RDS gene in

22 Kajiwara K, Hahn LB, Mukai S, Travis GH, Berson EL Dryja TP. Mutations in the human retinal degeneration Dryja TP. Mutations in the human retinal degeneration Nlow gene in autosoma

23 Wells J, Wrolebski J, Keen J, et al. Mutations in the human retinal degeneration slow (RDS) gene can cause eithe retinitis pigmentosa or macular dystrophy. Nature Genet 1993;3:213-18

24 Kajiwara K, Sandberg MA, Berson EL, Dryja TP. A null mutation in the human peripherin/RDS gene in a family with autosomal dominant retinitis punctata albescens. Nature Genet 1993;3:191-204.

25 Nichols BE, Sheffield VC, Vandenburgh K, Drack AV, Kimura AE, Stone EM. Butterfly shaped pigment dystrophy of the fovea caused by a point mutation in codon 167 of the RDS gene. Nature Genet 1993;3:202-7. 